\title{
Comparative study of dissimilar tailor-welded blanks between DP590 and DP980 dual phase steels
}

\author{
Rittichai Phaoniam ${ }^{1, *}$, Jesada Kaewwichit ${ }^{1}$ and Komgrit Lawanwong $^{2}$ \\ ${ }^{1}$ Department of Mechanical and Industrial Engineering, Faculty of Engineering, Rajamangala University of Technology Krungthep, \\ Bangkok, Thailand \\ ${ }^{2}$ Department of Production Engineering Technology, Faculty of Industrial and Technology, Rajamangala University of Technology \\ Rattanakosin, Prachubkirikhan, Thailand
}

\begin{abstract}
This research aims to study the dissimilar tailor-welded blanks between DP590 and DP980 dual phase steels using the autonomous GTAW process. The summarized results are as follows. It was found that utilized welding parameters in DP590 and DP980 steel butt joint were able to achieve complete penetration joint and there were not any defects. Furthermore, the dissimilar weld zone produced the hardness profile value between the DP590 and DP980 base metal. In particularly, DP590-HAZ region resulted in harden zone. Meanwhile, DP980-HAZ region induced a soften zone. By the way, the harden DP590-HAZ exhibited fine columnar martensite with a ferrite matrix. On the other hand, the soften DP980-HAZ represented a tempered martensite structures. Comparing the tensile test was carried out in order to investigate dissimilar welded joint strength in the different rolling directions. It was suggested that the specimen welded along to rolling direction was evidently larger tensile strength (1092 MPa) than the welding transverse to rolling direction $(638 \mathrm{MPa})$. Moreover, the weakest fracture occurred apparently on the region of DP590-BM rather than the HAZ region.
\end{abstract}

\section{Introduction}

In recent years, automotive industry is concerned with energy saving, to reduce in the vehicle weight as a focus concern in the automobile industry. This was the concept of Tailor-welded blanks (TWBs) has been applied to the various materials. TWBs consist of two or more sheets of material with different properties such as thickness, material, strength, surface coating or uncoating and different formability properties. [1] In addition, Dual phase (DP) steel is now widely used for fabricating automotive components such as frames, wheels, and bumpers as they offer a good combination of high strength and ductility.[2] Furthermore, from the literature review a research related on the DP steels welded with other steels and the dissimilar DP steels or the similar DP steels such as [3-5] laser welding DP780 and DP980 high strength steel joints, Friction Stir Welding DP590 steel, resistance spot welding of DP590 steel and other researches. However, such works have not siginificantly reported in the combined joints between DP590 and DP980 steels. Consequently, the purpose of this study aims to investigate the dissimilar tailor-welded blanks between DP590 and DP980 dual phase steels. This work is beneficial for the development of future automotive technology.

\section{Materials and methods}

In this work, dissimilar joints between DP590 and DP980 dual phase steels were carried out with gas tungsten arc welding process (GTAW). Chemical compositions of used materials at room temperature shown in Table 1

Table 1. Chemical compositions of experimental (wt $\%)$

\begin{tabular}{cccccccccccc}
\hline Materials & $\mathbf{C}$ & $\mathbf{S i}$ & $\mathbf{M n}$ & $\mathbf{P}$ & $\mathbf{S}$ & $\mathbf{A l}$ & $\mathbf{V}$ & $\mathbf{B}$ & $\mathbf{C u}$ & $\mathbf{C r}$ & $\mathbf{F e}$ \\
\hline DP590 & 0.12 & 0.40 & 1.60 & 0.025 & 0.010 & 0.015 & 0.2 & 0.005 & 0.2 & - & Bal. \\
\hline DP980 & 0.177 & 1.426 & 1.386 & 0.019 & - & - & - & - & - & 0.031 & Bal. \\
\hline
\end{tabular}

\footnotetext{
* Corresponding author: rittichai.p@mail.rmutk.ac.th
} 
As for the welding method, GTAW process was employed in order to autogenously butt weld joints between dual phase steels. Welding procedure was divided into two cases, namely, 1) a specimen welded along to rolling direction, and 2) a specimen welded transverse to rolling direction as illustrated in Fig. 1 a) and b) respectively. Unique device with backing argon gas, backing cupper plates, and clamping locks was used during welding in order to accomplish appropriate weld quality as shown in Fig $1 \mathrm{c}$ ). Before welding, these specimens were polished to eliminate undesired oxides on surfaces. Then, acetone was applied. During welding, specimens were clamped to prevent distortion. Specimen size and utilized welding conditions were set as Table 2. After joining, welded specimens were cut through electrical discharge machining (wire-cut EDM) for determining mechanical properties. Welded specimen geometry for tensile test was given as Fig.2 a) the welding along to rolling direction, and Fig. 2 b) the welding transverse to rolling direction. Shimadzu Auto Graph AG-X plus Tensile tester

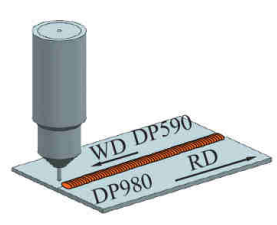

a) Longitudinal weldingwith rolling direction

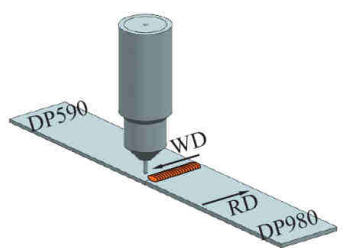
with rolling direction b) Transverse welding-

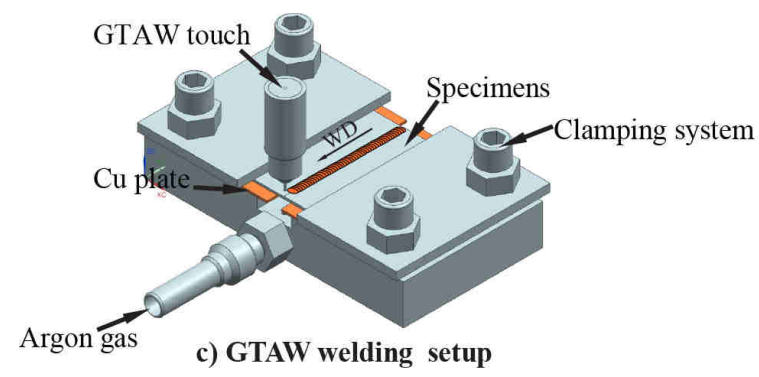

Fig. 1. Schematic representation of the GTAW setup

Table 2. Utilized welding conditions

\begin{tabular}{c|c}
\hline \multirow{2}{*}{ Base metal } & DP590 $(60 \mathrm{~mm} \times 20 \mathrm{~mm} \times t 1 \mathrm{~mm})$ \\
\cline { 2 - 2 } & DP980 $(60 \mathrm{~mm} \times 20 \mathrm{~mm} \times t 1.2 \mathrm{~mm})$ \\
\hline Welding current & $50 \mathrm{~A}$ \\
\hline Shielding gas & Pure argon \\
\hline Gas flow rate & $15 \mathrm{~L} / \mathrm{min}$ \\
\hline $\begin{array}{l}\text { Electrode } \\
\text { extension }\end{array}$ & $5 \mathrm{~mm}$ \\
\hline Arc length & $2 \mathrm{~mm}$ \\
\hline Welding speed & $6 \mathrm{~mm} / \mathrm{sec}$ \\
\hline Ceramic nozzle & $\varnothing 6 \mathrm{~mm}$ \\
\hline
\end{tabular}

In addition, hardness profile along the cross-section weld from DP590 to DP980 was measured with micro-vickers hardness tester (Matsuzawa MMT-X3). Measuring point interval was given as indent spacing of $0.1 \mathrm{~mm}$. with applied load of 100 grams, as well as hold time of 10 seconds. In microstructure examination according to ASTM E407 standards, the cross-sections of the welds were polished using an automatic polishing machine and then etched with $2 \%$ nitric acid solution for about 5-10 sec. Then, three different regions of the welded specimen were comparatively observed for metallurgical microstructures with optical microscopic (Leica DM$2500 \mathrm{M}$ ), namely the base metals, the dissimilar weld metal, and the heat affected zone (HAZ).

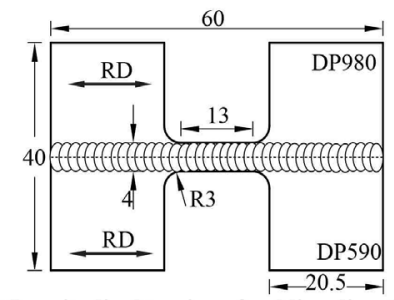

a) Longitudinal tension of welding direction.

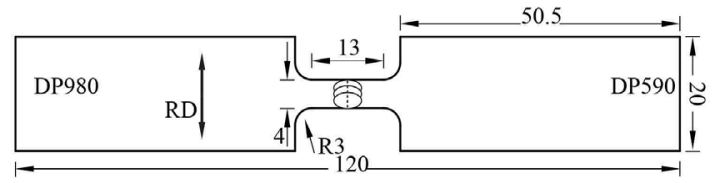

b) Transverse tension of welding direction.

Fig. 2. Welded specimen dimension of tensile test,

a) Welding along to rolling direction,

b) Welding transverse to rolling direction. (Unit: $\mathrm{mm}$ )

\section{Results and discussion}

\subsection{Weld surface observation}

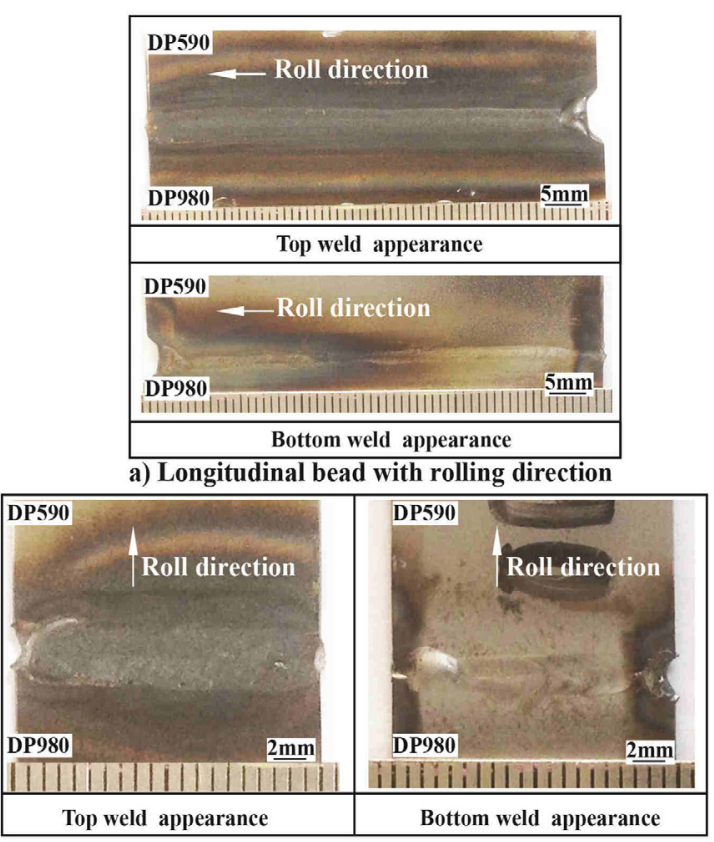

b) Transverse bead with rolling direction

Fig. 3. Macroscopic morphology of dissimilar tailor welded blanks (TWBs)

After experimented with GTAW, the weld surface appearances of top and bottom side are exhibited as Fig. 3 a) the welding along to rolling direction and Fig. 3 b) 
the welding transverse to rolling direction. As a result, it revealed that the weld was full penetration. The weld surface neither have undesired oxide films nor any defects. These evidences testified to appropriate welding conditions and pursuing gas system as well.

\subsection{Mechanical properties}

\subsubsection{Hardness}

In order to investigate the evolution of mechanical properties in the dissimilar tailor welded blanks between DP590 and DP980 steels, Fig. 4 exhibited hardness profile along the cross-section weld. It was found that the hardness value of the dissimilar weld was approximately 300-400 HV. Such hardness value was between the base metal of DP590 (217 HV) and DP980 (426 HV). However, particularly in HAZ, it evidently revealed that DP590-HAZ region induced the hardness value more than its base metal. And then, gradually decreasing approach to its base metal. This increased hardness is probably caused by critical cooling rate nearby the dissimilar weld during welding.

In contrast, DP980-HAZ region exhibited the soften zone with the hardness value lower than its base metal. This decreased hardness was probably due to the tempering treatment during welding $[6,7]$. As a result, it strongly indicated fluctuating characteristics of dissimilar tailor welded blanks, especially in HAZ.

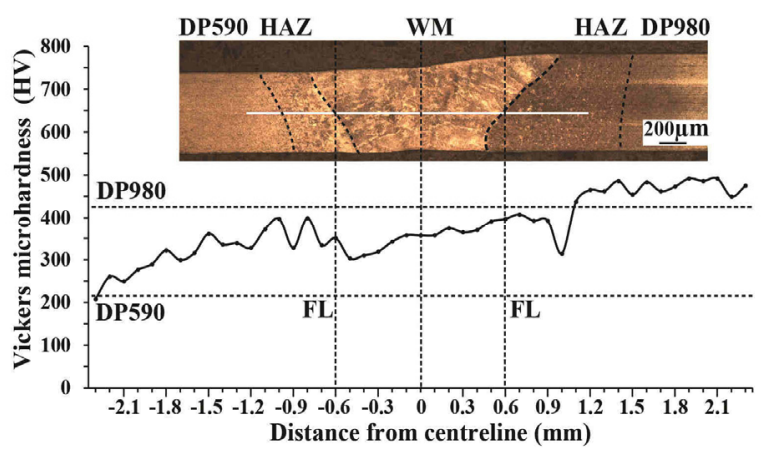

Fig. 4. Distribution profile of hardness value of dissimilar tailor-welded blanks.

\subsubsection{Tensile strength.}

A comparative study between the specimens welded along and transverse to rolling direction was carried out through tensile test. Engineering stress-strain curves are represented in each case as Fig. 5. Consequently, it clearly revealed that the specimens welded along to rolling direction induced a superior tensile strength (1092 MPa), and yield point (692 MPa) as well. On the other hand, it is noticed that such tensile strength is close to DP980 properties. Whilst, the specimens welded transverse to rolling direction encouraged slightly more elongation. This welding case contributed to tensile strength of $638 \mathrm{MPa}$ and yield point of $438 \mathrm{MPa}$. In addition, the fracture characteristics were substantially considered. It was found that, in case of welding along to rolling direction, the fracture location occurred at the central dissimilar weld. This result was able to prove the strength of longitudinal dissimilar weld. On the other hand, welding transverse to rolling direction, the fracture was apparently located on the region of DP590 base metal rather than HAZ or dissimilar weld. It was remarkably noticed welding with a given conditions could not influence on the strength of HAZ regions.
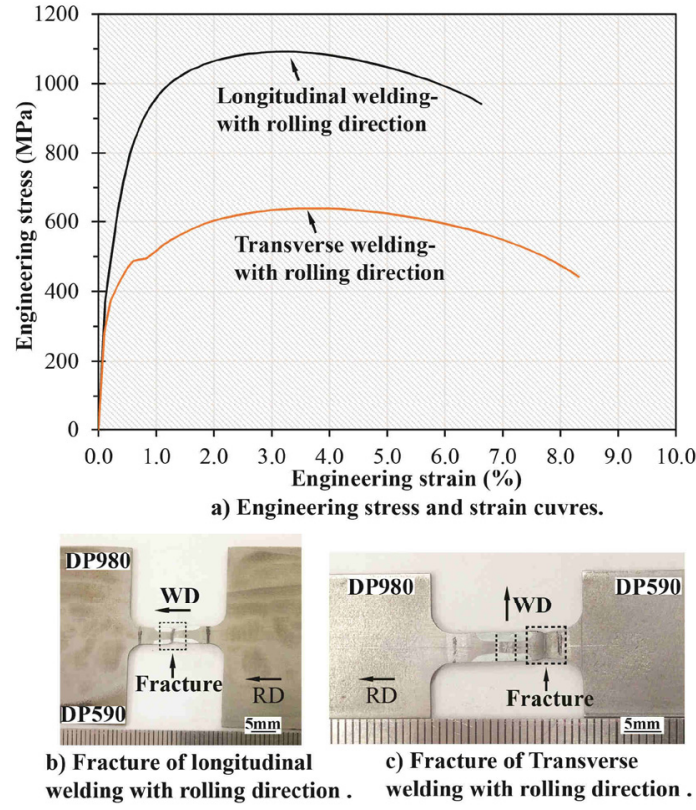

Fig. 5. Comparison of engineering stress and strain curves. a) Engineering stress and strain curves,

b) Fracture of longitudinal welding with rolling direction.

c) Fracture of transverse welding with rolling direction.

\subsubsection{Microstructure morphology.}

Figure 6 exhibits typically cross-sectional weld in the case of welding transverse to rolling direction. Microstructures on each region were compared to each other, namely dissimilar weld metal (WM), DP590HAZ, DP590 base metal (DP590-BM), DP980-HAZ, and DP980 base metal (DP980-BM). As a result, welding with a given conditions was able to attain complete penetration weld. There were no imperfections like porosity or impurity inclusion as represented in Fig. 6 a) Whilst, Fig. 6 b) and c) represents typical morphology of DP590 and DP980 base metal which consist of a ferrite matrix with martensite particles. It can be observed that the matrix structure in DP980 was coarser than DP590 base metal. In the dissimilar weld, this region was re-melted in order to combine between DP590-BM and DP980-BM. Therefore, microstructure characteristics in the fusion zone were radically evolved. As Fig. 6 c), WM exhibits columnar grained martensite along the ferrite matrix in re-melted region. This was the reason why there was the hardness transfiguration in the weld as mentioned before. Aside, DP980-HAZ exhibited a tempered martensite structures. For that reason, lower hardness in DP980-HAZ than DP980-BM was significantly induced. On the contrary, fine columnar martensite with a ferrite matrix was found in DP590HAZ. These evidences encouraged to increasing 
hardness more than DP590-BM. As a consequence, it was particularly noticed that thermal distribution during welding effects on HAZ in different ways.

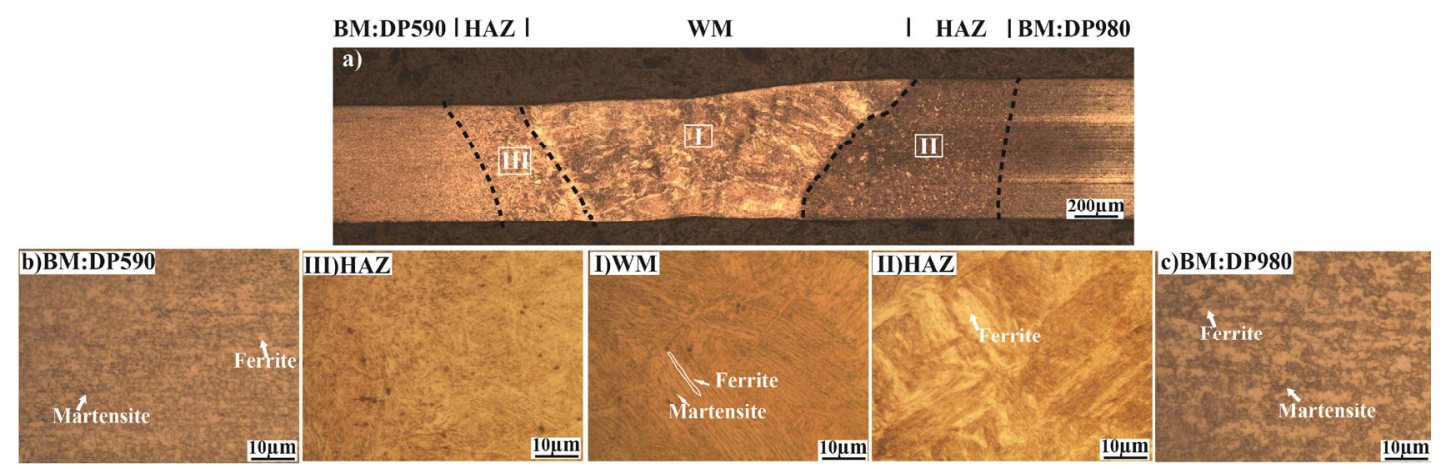

Fig. 6. Overview of microstructural weld joint and each position of weld metal a) dissimilar weld joint b) BM DP590 c) BM DP980

\section{Conclusions}

This paper describes the study of dissimilar tailorwelded blanks between DP590 and DP980 dual phase steels using GTAW process. The remarkable investigations can be summarized as follows.

1) According to the utilized GTAW condition and pursuing gas system, it revealed that DP590 and DP980 steels butt joint was able to achieve complete penetration joint. There were not any defects and undesired oxide films. Weld bead appearance was smoothly blended.

2) In hardness profile, dissimilar tailor-welded blanks exhibited strongly fluctuating characteristics. In other words, the dissimilar weld hardness value was between the DP590 and DP980 base metal. In particularly, DP590-HAZ region increased hardness value while DP980-HAZ region induced a soften zone.

3) The harden DP590-HAZ was testified through fine columnar martensite with a ferrite matrix. On the other hand, the soften DP980-HAZ represented a tempered martensite structures. Microstructure evolution was strongly caused by thermal distribution during welding and distinguished material characteristics.

4) Tensile test was carried out in order to investigate dissimilar welded joint strength in different rolling directions. It revealed that the welding along to rolling direction produced virtually greater tensile strength of the welded specimen than the welding transverse to rolling direction. Furthermore, the weakest fracture occurred apparently on the region of DP590-BM rather than HAZ.

In the future, additional investigations should be conducted with computational welding simulation in order to demonstrably understand thermal distribution in HAZ which influences harden or soften zone.

\section{Acknowledgments}

The authors thank the research and development institute of Rajamangala University of Technology Krungthep for project funding and support.

\section{References}

[1] A. Zadpoor, J. Sinke, and R. Benedictus, Mechanics of Tailor Welded Blanks: An Overview vol. 344, 2007.

[2] J. H. Lee, S. H. Park, H. S. Kwon, G. S. Kim, and C. S. Lee, "Laser, tungsten inert gas, and metal active gas welding of DP780 steel: Comparison of hardness, tensile properties and fatigue resistance," Materials \& Design, vol. 64, pp. 559-565, 2014/12/01/ 2014.

[3] S. Gao, Y. Li, L. Yang, and W. Qiu, "Microstructure and mechanical properties of laser-welded dissimilar DP780 and DP980 highstrength steel joints," Materials Science and Engineering: A, vol. 720, pp. 117-129, 2018/03/21/ 2018.

[4] H. S. Di, Q. Sun, X. K. Nie, X. N. Wang, and X. M. Chen, "Mirostructure and properties of laser welded joints of dual phase and press-hardened steels," Procedia Engineering, vol. 207, pp. 16651670, 2017/01/01/ 2017.

[5] B. Wang, L. Hua, X. Wang, and J. Li, "Effects of multi-pulse tempering on resistance spot welding of DP590 steel," The International Journal of Advanced Manufacturing Technology, vol. 86, pp. 2927-2935, 2016/10/01 2016.

[6] K. Bandyopadhyay, S. K. Panda, P. Saha, and G. Padmanabham, "Limiting drawing ratio and deep drawing behavior of dual phase steel tailor welded blanks: FE simulation and experimental validation," Journal of Materials Processing Technology, vol. 217, pp. 48-64, 2015/03/01/ 2015.

[7] W. Xu, D. Westerbaan, S. S. Nayak, D. L. Chen, F. Goodwin, and Y. Zhou, "Tensile and fatigue properties of fiber laser welded high strength low alloy and DP980 dual-phase steel joints," Materials \& Design, vol. 43, pp. 373-383, 2013/01/01/ 2013. 